\title{
Study of Spatial Differentiation of Human Capital in Russian Regions in the Context of Digital Economy Development
}

\author{
Oveshnikova L.V.* \\ Plekhanov Russian University of Economics \\ Moscow, Russia \\ e-mail: Oveshnikova.LV@rea.ru \\ Sibirskaya E.V. \\ Plekhanov Russian University of Economics \\ Moscow, Russia \\ e-mail: Sibirskaya.EV@rea.ru
}

\author{
Pasynkova O.M. \\ Voronezh State University of Engineering Technologies \\ Voronezh, Russia \\ e-mail: pasol-30@mail.ru
}

\author{
Chaikovskaya L.N. \\ Voronezh State University of Engineering Technologies \\ Voronezh, Russia \\ e-mail: lubovdmitr@yandex.ru
}

\author{
Duvanova Yu.N. \\ Voronezh State University of Engineering Technologies \\ Voronezh, Russia \\ e-mail: dyvanova@mail.ru
}

\begin{abstract}
The authors consider the indicators of human capital development in the context of Russian regions to study the potential of digital economy. The content and form of manifestation of human capital in digital economy is revealed. The analysis of statistical data on the state of human capital in the development of digital economy in Russia is carried out. Substantial spatial differentiation is substantiated, caused by sharp differences in the level of human capital development in regional centers and peripheries. It is noted that the active and rational development of human capital implies a proclaimed course in the country for modernization and innovative development, since any systematic transformation of the economy requires orientation to the development of human capital and the formation of its new quality. It is in the field of human capital that the main socio-economic advantages of Russia in digital economy are concentrated.
\end{abstract}

Keywords - human capital, innovation, digital economy, human development index, regions of the Russian Federation.

\section{INTRODUCTION}

Human capital in almost all countries of the world exceeds half the accumulated national wealth. The developed economies of the leading countries of the world are fighting for the formation of a new economy - the economy of knowledge, innovation, global information systems, the latest technology and venture business. The basis of such an economy is human capital, which is the main driving force of the socio-economic development of modern society [5].

Today, human capital occupies a major place in the country's economy, since it is its attraction that contributes to the transition to the innovative path. Digital economy is developing non-stop. Its development contributes to a change in the place and role of man in the new type of economy. This is manifested in the fact that human skills and abilities have become a determining factor in social production. In the knowledge-based economy, intangible assets and investments in human capital are considered as the most important components of the development of the digital economy. In recent years, the importance of resources based on human knowledge has especially grown: accumulated human capital is a tool for determining the development path of both the country's economy and the activities of any organization.

Human capital is an important factor shaping the organization's innovative potential in the context of the development of digital economy. One of the most significant indicators for measuring human capital is innovation and the current policy of an innovative economy in the country. The role of the digital economy is greater than ever: every developed country is trying to enter the world stage with its own knowledge and methods and be the most competitive compared to others [1].

The economic category of "human capital" is considered both in a narrow and broad sense, in connection with which three areas can be distinguished that characterize the concept of human capital: professional (professional knowledge, skills, labor skills); capital of culture (includes general culture, motivation, human behavior within the framework of morality, law and the possibility of social interaction); health capital (general health, physical and moral condition of the individual) [3].

Thus, we can say that human capital is considered such capital, which is represented in the individual by the potential ability to generate income based on intellectual abilities, as 
well as knowledge and practical skills acquired in the process of training, education and practical activities of a person.

To assess human capital in Russia, it is necessary to conduct a detailed analysis by reviewing and evaluating each region and its innovation policy. The Russian Federation is developing under conditions of increasing limited labor resources, the replenishment task of which can be solved by improving their quality, i.e. increasing the level of development of human capital in the Russian regions [2].

In accordance with the integration of national projects in the public administration system, the development of an innovative economy and the resulting shortage of skilled workers in the Russian Federation, there is a need for an internal analysis of human capital in the country, its assessment at the regional level and the search for solutions to emerging problems [4].

In connection with the transformation of the modern world and the development of the socio-economic situation in Russia, it is impossible to take into account the degree of all risks and objectively assess the situation of human capital in the country: analysis and comprehension of a large amount of information is required, which is impossible without the use of multivariate statistical analysis. Both abroad and in our country, this scientific direction is actively developing, but, despite this, it is impossible to fully quantify the levels of development of human capital within the country, that is, in its regions. Therefore, the analysis requires a more detailed study using a scientific approach and a qualitative assessment of the territorial levels of human capital development.

\section{MATERIALS AND METHODS (MATERIALS FOR USAGE, DESCRIPTION OF THE SUBJECT AREA, METHODS AND TECHNIQUES OF RESEARCH)}

The methodological basis of the study consists of scientific and statistical methods: the method of scientific generalizations, the grouping method, the method of correlation analysis, the method of linear regression modeling, the method of predictive analysis. The research information base was made up of official statistical reports provided by the Federal State Statistics Service (Rosstat), the Ministry of Economic Development of the Russian Federation, the Ministry of Labor and Social Protection, as well as calculated indicators for these data and information obtained from periodicals and resources of the global Internet network. The analysis of the results of these methods was carried out in the following software packages: MS Excel, R, Gretl.

To study the level of development of human capital in the Russian Federation and the regions, the following quantitative indicators were selected: socio-economic indicators, financial indicators, education indicators, indicators of science and innovation, health indicators, indicators of culture and sports.

The development of human capital in many respects depends on the individual's standard of living, therefore, it is necessary to study a number of indicators, for example, incomes and expenses of the population (structure and sources), expenses of the population in the main areas (education, health, sport, culture), differentiation of the population by income level, average accrued salary.
A special place among the considered indicators is occupied by the HDI - an integral indicator of assessing the development of human potential, which in turn reflects the development of human capital. It includes three components life expectancy, literacy rate and gross national income per capita.

In Russia, this indicator is calculated both at the federal and regional levels. The information base is data published by the Federal State Statistics Service, as well as ministries and departments of the Russian Federation [6].

Note that there is no single approach to the statistical accounting of human capital. To study the development of human capital at the regional level, it is necessary to rely on the experience of the developed quantitative methods, as well as on the methods of multivariate statistical analysis.

\section{RESULTS}

To assess the differences in the values of characters in the studied populations, a hypothesis was put forward on the high degree of differentiation of the regions of the Russian Federation in terms of the level of development of human capital. For example, the population of the Russian Federation is distributed unevenly across the regions: the highest concentration of people is observed in Moscow, where 4926 people live per square kilometer, and the lowest concentration is in the Chukotka Autonomous Okrug (0.07 people per 1 $\mathrm{km}^{2}$ ).

For the "population" indicator in 2018, the difference between Moscow and the Nenets Autonomous Okrug is 12,463 thousand people, and the coefficient of variation is 102 $\%$, which shows heterogeneity and differentiation among the regions of the Russian Federation. It is worth noting that every year the difference between the maximum and minimum values only increases. For the "labor force" indicator, the range of variation is 7,164 thousand people, and the coefficient of variation is $109 \%$, which also has an upward trend.

Considering the Human Development Index for the regions of the Russian Federation, there is homogeneity in the aggregate (in 2018, the coefficient of variation is $3 \%$ ). A homogeneous population is also observed for such an indicator as "life expectancy" - the coefficient of variation is about $1 \%$.

The coefficient of variation for the indicator "average per capita income" in 2018 is $40 \%$, which shows differentiation among the regions of the Russian Federation. The range of variation for this indicator is 57657 rubles. Despite this, the gap between the regions with the highest average per capita incomes and the lowest average per capita incomes is observed annually.

For the Gross Regional Product indicator, the coefficient of variation for the period under review was less than $33 \%$, which means the homogeneity of the grouping under consideration. Despite this, the difference between the leading region (Moscow) and the most lagging region (Altai Republic) is significant: $15,680.3$ billion rubles. Also, the aggregate is homogeneous for the indicator "Investments in fixed assets", 
where in the period from 2005 to 2018 , the coefficient of variation was about $2 \%$.

"Internal costs for research and development" also turned out to be among the indicators with a homogeneous set of regions, although the maximum value (Moscow) for this indicator exceeds the minimum (Nenets Autonomous Okrug) by 17057 times.

In terms of the "Number of higher education and scientific organizations" indicator, the indicator of variation in 2018 reached $201 \%$, although it was the smallest among all studied years. In Chukotka Autonomous Okrug, not a single organization of higher education was identified, and in Moscow - 161 educational institutions. The aggregate under consideration is also heterogeneous for the indicator "Graduate Specialists", where the coefficient of variation in the period from 2005 to 2018 was about $200 \%$. The range of variation for this indicator was 200.2 thousand people.

The difference between Moscow and the Nenets Autonomous Okrug (maximum and minimum values) for the indicator "The number of personnel engaged in research and development" in 2018 amounted to 224,495 people, and the coefficient of variation was $313 \%$, which proves a high differentiation among the regions under consideration . A high coefficient of variation was also observed for the indicator "Number of doctors", where the maximum value was observed in $2011-127 \%$, and as of the end of 2018 , the coefficient of variation was $114 \%$. The range of variation for this indicator was equal to 69.7 thousand people.

The indicator "Patent application filing" in the Russian Federation is also characterized by a high level of regional differentiation. The coefficient of variation for the period under review ranges from $210 \%$ to $270 \%$, and the range of variation for submitted applications was 5545 units, and for issued - 5925 units.

The heterogeneity of the regions is also observed for the indicator "The number of organizations performing research and development" - the coefficient of variation in 2018 was $189 \%$, and the difference between Moscow and Chukotka Autonomous Okrug and Jewish Autonomous Okrug was 746 units.

The coefficient of variation for the indicator "Costs of technological innovation" in the Russian Federation in 2018 amounted to $186 \%$, and the range of variation was 194,204 million rubles. Also, there is a high differentiation of regions in terms of the number of sports facilities - the coefficient of variation increases annually and at the end of 2018 amounted to about $110 \%$. Regional differentiation is also observed for the indicator "The number of theater spectators", where the coefficient of variation for the period from 2005 to 2018 was approximately $50 \%$, and the difference between the leading region (St. Petersburg) and the most lagging region (Altai Republic) amounted to 724 people.

For the indicator "Number of visits to museums", the coefficient of variation in 2018 was $104 \%$, and the range of variation was 4,911 people.

The coefficient of variation for the indicator "Costs of technological innovation" in the Russian Federation in 2018 amounted to $186 \%$, and the range of variation was 194,204 million rubles. In addition, there is a high differentiation of regions in terms of the number of sports facilities - the coefficient of variation increases annually and at the end of 2018 amounted to about $110 \%$. Regional differentiation is also observed for the indicator "The number of theater spectators", where the coefficient of variation for the period from 2005 to 2018 was approximately $50 \%$, and the difference between the leading region (St. Petersburg) and the most lagging region (Altai Republic) amounted to 724 people. For the indicator "Number of visits to museums", the coefficient of variation in 2018 was $104 \%$, and the range of variation was 4,911 people.

At this stage of the study, a high differentiation of regions in the Russian Federation is already noticeable in almost all indicators.

Analyzing abnormal values for the studied indicators in 2018, the largest share falls on Moscow, St. Petersburg, the Tyumen region, Moscow region, the Khanty-Mansi Autonomous Okrug Ugra, Chukotka Autonomous Okrug, the Republic of Ingushetia and the Chechen Republic. It should be noted that the anomalous values of the indicators of the Republic of Ingushetia and the Chechen Republic occupy the maximum positions in the considered indicators of the level of health, which testifies to the high longevity of the population of these regions, and such regions as Moscow, Moscow Region and St. Petersburg - in terms of education, socio-economic status, culture, migration and innovative technologies, which undoubtedly are the main factors in the formation of human capital.

Thus, based on the results obtained, we conclude that the totality of the values of indicators characterizing the factors and the level of development of human capital is heterogeneous: this indicates the complexity of the processes taking place in the territorial system, subject to various socio-economic laws.

In the process of assessing human capital, it is important to understand in which direction both Russia as a whole and its regions are developing. In order to identify certain trends, a tool such as forecasting is used - the identification and prediction of objective trends in the development or outcome of a particular process, the development of the country's economy as a whole, scientifically based proposals based on a system of cause and effect relationships and patterns.

Forecasting is necessary to determine the course of action in the economy, followed by the formulation of a set of measures for their implementation, which is reflected in state laws, programs and priority projects.

To predict the Human Development Index, the linear regression method was used, which is based on the analysis of the relationship of two variables (pair correlation method) the effect of variation of the factor indicator $x$ on the effective indicator $y$. In the final version of the model, the following regressors were obtained: $\mathrm{x} 3$ (percentage of labor force), $\mathrm{x} 4$ (migration growth rate), x6 (average income per capita), x7 (population per 1 hospital bed), $x 8$ (investment in fixed assets), $\mathrm{x} 9$ (the percentage of graduates of senior management), $\mathrm{x} 15$ (number of spectators of theaters), $\mathrm{x} 17$ (number of sports facilities). The analysis showed that in all 
regions of the Russian Federation there is a positive trend for the HDI, and this index will increase every year.

All factors except $x 7$ are linear and direct with respect to the HDI. The population index per 1 hospital bed reflects an inverse relationship with an effective sign. The resulting model was tested for significance using the Fisher test, which showed the possibility of using regression in further analysis. $\mathrm{R}^{\wedge} 2$ for the resulting model is 0.7 , respectively $70 \%$ of the HDI dispersion is explained by the regression equation, which is a good result.
Let us present the results of forecasting the HDI using the example of Moscow and St. Petersburg. Thus, in Moscow, the human development index in 2019 will be 0.97 , in 2020 also 0.97 , and by $2021-0.98$. This is the highest rate compared to other regions (Fig. 1).

In St. Petersburg, the HDI forecast for 2020 will be 0.97 , and in $2021-0.98$, which is a similar forecast to Moscow. It is worth noting that for both cities in 2009 there was a sharp jump, and then a linear trend recovery (Fig. 2).

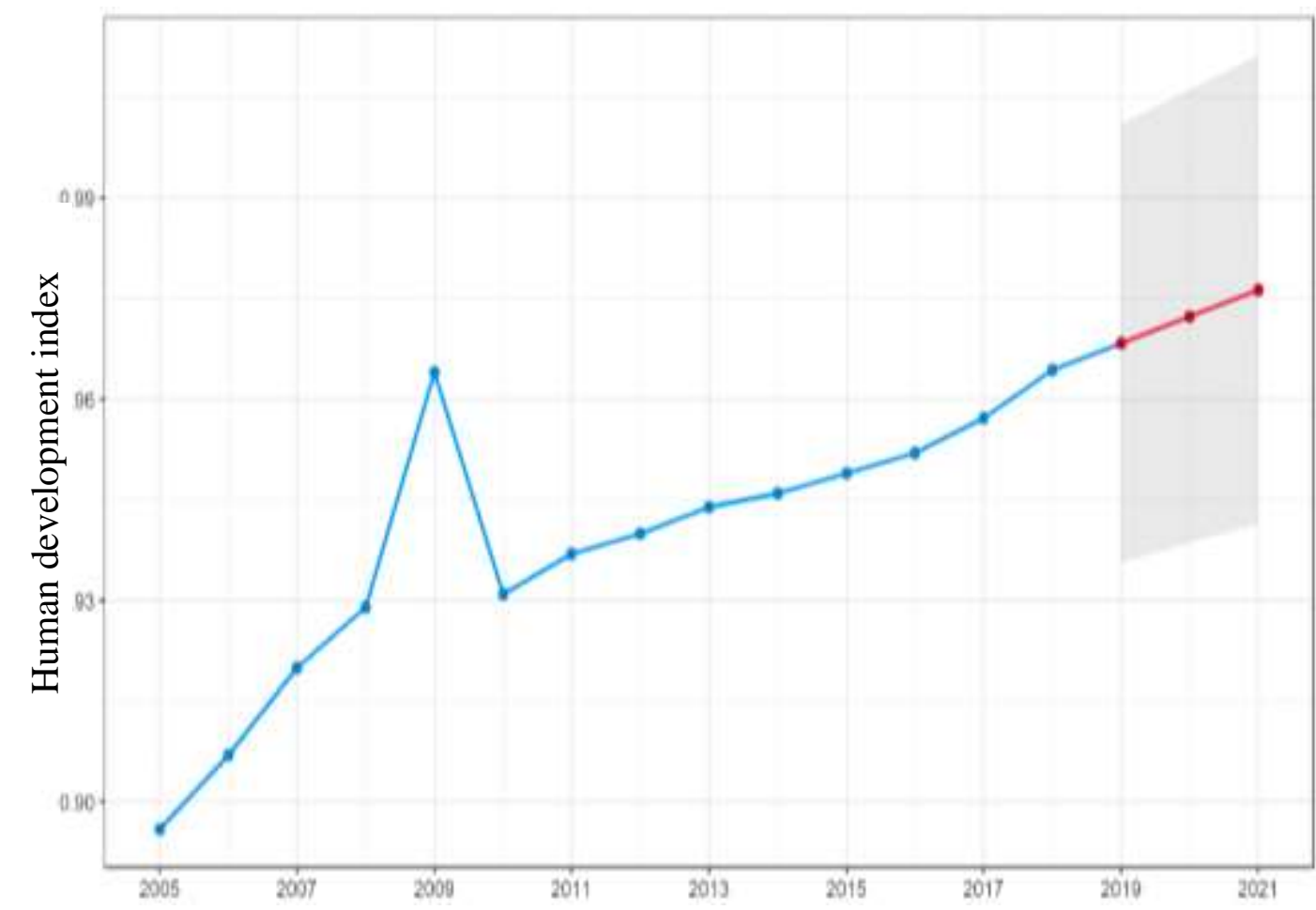

Fig. 1. Dynamics and forecast of the HDI for Moscow until 2021

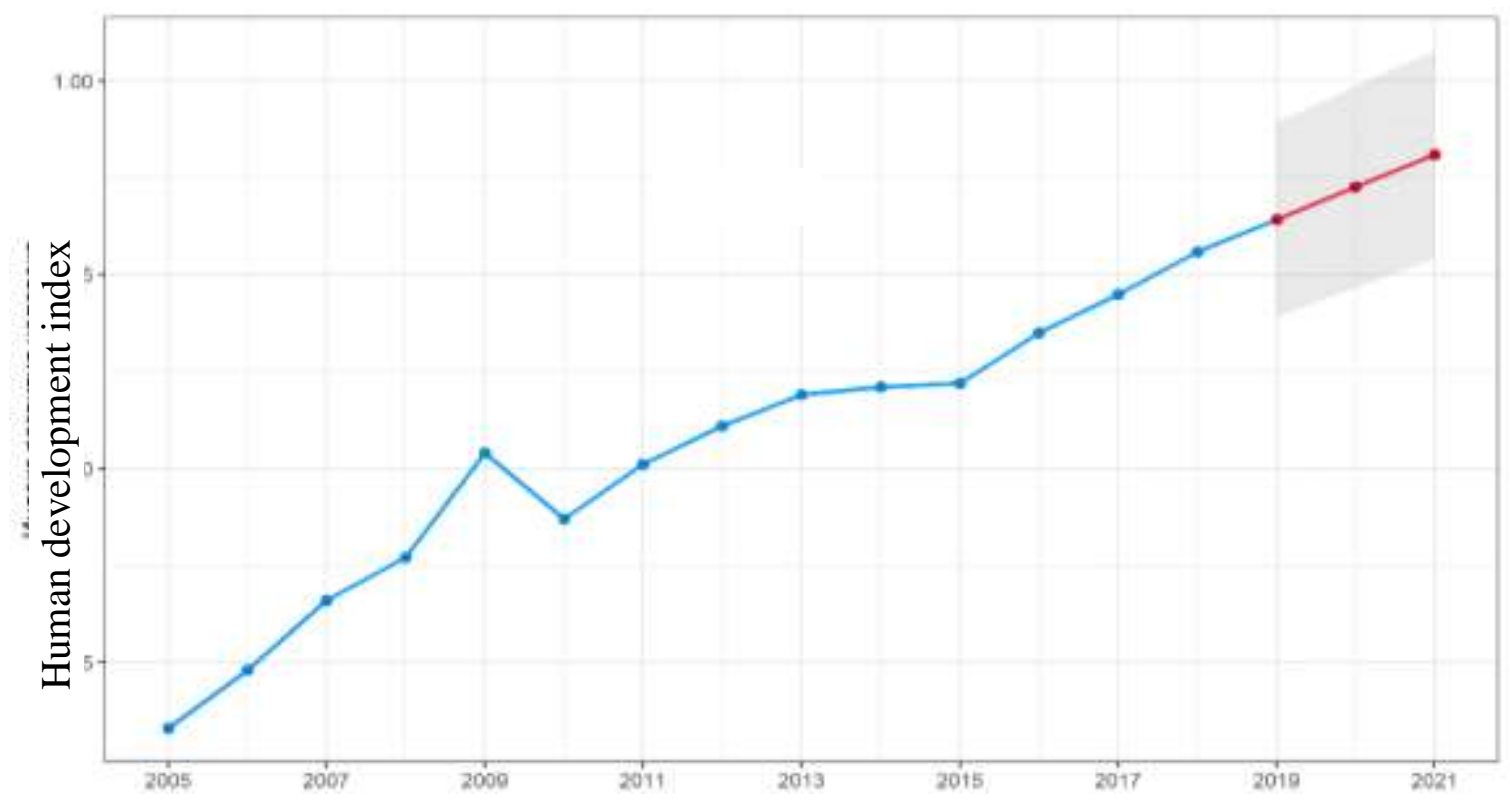

Fig. 2. Dynamics and forecast of the HDI for St. Petersburg until 2021 
In terms of the HDI, the Russian Federation has a positive tendency, strengthening its position on the world stage. Considering the regions of the Russian Federation, it can be noted that all the studied values have a positive linear trend.

\section{CONCLUSION}

Considering the dynamics of the studied indicators, we can distinguish leading regions and lagging regions: the first group included such regions as Moscow, St. Petersburg, the Moscow region, the Tyumen region, and the second - the Altai Republic, Chukotka Autonomous Okrug, Nenets Autonomous Okrug, Jewish Autonomous Oblast and the Republic of Ingushetia.

The hypothesis is confirmed that the level of human capital in the Russian Federation varies greatly depending on the region. There are strong differences between the leading regions and the "lagging" regions in almost all the studied indicators, which requires paying special attention to the development of areas such as increasing the cash income of the population, investing in fixed assets, raising the level of education, as well as social infrastructure.

In general, the development of the digital economy can be considered a challenge for the institution of human capital development, since it is an important tool to increase competitiveness and stimulate the innovative development of the state. With the proliferation of digital production and digital services, countries in which the possibilities of human capital are adapted to a new reality gain additional benefits. In this regard, in order to smooth out regional inequalities in the development of the digital economy, it is advisable for the authorities to monitor and adjust indicators that reflect the prospects for ensuring a high level of human capital in the regions.

\section{References}

[1] V. Barkhatov, D. Pletnev, A. Kampa, "Actual situation and future perspectives about smes's human capital in Russia and other countries", Europ. J. of busin. and econ., vol. 2, pp. 1-4, 2016.

[2] I.A. Gurban, "National human capital of Russia: regional differentiation", Fundamental res, no. 5-5, pp. 1063-1069, 2014.

[3] A.N. Dobrynin, S.A. Dyatlov, Human capital in a transitive economy: formation, assessment, use efficiency. St. Petersburg: Science, 2006, 309 p.

[4] Yu.Sh. Kapkaev, I.P. Dobrovolsky, "The influence of factors of the socio-economic environment on the standard of living of the population", J. Chelyab. state un-that, vol. 11, no. 366, pp. 56-63, 2015.

[5] T.M. Regent, "Problems and opportunities of the human Capital for the digital economy of Russia" [Int. scientific Conf., dedicated to the 90th anniversary of S.P. Kapitsa Human Capital in the Digital Economy Format, 432 p. 2018] (Moscow, 16 February 2018). Moscow: The publ. house of RosNOU.

[6] Federal State Statistics Service. Retrieved from: http://www.gks.ru 